\title{
Cultura, acción colectiva y cambio institucional
}

\author{
Gonzalo Castañeda*
}

\section{RESUMEN}

Este artículo presenta una teoría que analiza la propagación de variantes culturales que inducen la cohesión al interior de la sociedad civil y, por ende, fortalecen la capacidad de un país para resolver problemas de acción colectiva. El modelo combina elementos de la teoría de juegos evolutivos con un concepto de solución para comportamientos estratégicos en donde los actores toman decisiones secuenciales en un contexto de racionalidad acotada. Con este enfoque es posible explicar la coevolución de los valores culturales contemporáneos con variables económicas y políticas, así como la importancia del legado histórico en el establecimiento de las trayectorias de desarrollo de cada país. Asimismo, se argumenta que los planteamientos teóricos en economía requieren incorporar argumentos culturales para lograr una mejor comprensión de las inercias institucionales y las trampas de pobreza.

Palabras clave: acción colectiva, reformas institucionales, cultura, crecimiento económico y trampas de pobreza.

Número de clasificación JEL: O5, N1, B5, C7.

Este

induc

un pa

teorí:

$\cos$,

acota

conte

do hi

mo, s

gume

las tr

Núm

Palal mico

\section{Abstract}

This paper presents a socioeconomic theory that analyzes the propagation of cultural variants that induces the cohesiveness of civil society and, thus, improves society's capacity to solve collective action problems. The model combines tools of evolutionary game theory with a solution concept for strategic behavior where rationally bounded decisions are made sequential. With this framework, it is possible to explain the co-evolution of contemporary cultural values with economic/political variables, as well as the importance of the historical legacy in establishing the country's development path. Likewise, it is argued that economic theorizing requires cultural arguments for a better understanding of institutional inertias, lock-ins, and poverty traps.

Key words: Collective action, institutional reform, culture, economic growth and poverty traps.

Classification number JEL: O5, N1, B5, C7.

\section{ABS}

This

varia

ity to

theor

are $n$

conte

tance

is arg

of in

Num

Key

erty 1

*El Colegio de México. Correo electrónico: sociomatica@hotmail.com 


\section{INTRODUCCIÓN}

Resulta indudable que consideraciones de economía política son críticas para explicar las diferencias observadas en el crecimiento de largo plazo de países y regiones en el mundo. El argumento tradicional señala que el poder económico y político de las élites inhibe los avances tecnológicos y las reformas institucionales conducentes al crecimiento y a una mejor distribución del ingreso. Por lo general, esta inercia institucional se explica en términos de juegos estratégicos en los que las élites tienen mayores incentivos que los ciudadanos para construir coaliciones y diferentes formas de poder de facto (es decir, capacidad negociadora, fuerza bruta, cabildeo) (Acemoglu y Robinson, 2006 y 2007). Sin embargo, bajo este planteamiento el problema de acción colectiva que debilita la posición estratégica de la sociedad civil no forma parte del análisis. En otras palabras, el enfoque tradicional simplemente supone que los individuos que conforman la sociedad civil están fragmentados y, por ende, carecen de la capacidad de coordinación que es necesaria para impulsar sus agendas y el diseño institucional preferido.

La evidencia histórica muestra que unas sociedades han sido más exitosas que otras en lograr que los miembros de su sociedad civil (o contraélites) enfrenten de manera coordinada a las élites y el statu quo. De aquí que para tener un mejor entendimiento del desempeño socioeconómico diferenciado se requiere dar respuesta a la siguiente pregunta fundamental: ¿de qué manera una sociedad civil incrementa su cohesión y capacidad negociadora? Esta tarea resulta muy difícil de emprender en un enfoque que, como el neoclásico, descarta los procesos de inserción social y, por consecuencia, la incidencia del vector cultural en el desempeño colectivo. En contraste, en este artículo se ofrece una solución tentativa a esta interrogante al describir la capacidad de cohesión de las sociedades a partir de un proceso evolutivo.

En cualquier sociedad es común encontrar que las élites utilizan las herramientas que están a su alcance para bloquear reformas que pudieran perturbar el statu quo. Sin embargo, la distribución del poder varía de una comunidad a otra, ya que sociedades que hoy en día son consideradas avanzadas lograron en algún momento de su historia crear los contrapesos que permitieron la injerencia de la sociedad civil en el diseño de instituciones y políticas públicas. Estos contrapesos fueron, a su vez, resultado de la creciente participación de la sociedad civil y su mayor capacidad para aglutinar esfuerzos. Por tanto, la hipótesis principal de este artículo sugiere que ciertos valores culturales son necesarios para que los individuos se comporten de manera más participativa, y que estos valo- 
res se presentan cuando existen las condiciones socioeconómicas para ello. De esta forma, cuando la sociedad civil está más cohesionada y sus miembros más dispuestos a luchar por sus derechos y agendas, es más factible que se observen acciones coordinadas que incrementan su posición negociadora vis à vis las élites.

Aunque las élites son los actores que a fin de cuentas elaboran constituciones, establecen instituciones e implantan la política pública, en una sociedad participativa estas regulaciones reflejan indirectamente los intereses de la sociedad civil. Esto es así ya que las generaciones jóvenes de las élites han internalizado valores que son afines al sentir mayoritario, o bien porque la fuerza política de las élites ha sido condicionada por el peso político de la sociedad civil. En este artículo se asocia una actitud más participativa con la presencia de valores de autoexpresión, como los que definen Inglehart (1997) e Inglehart y Welzel (2005). Una sociedad favorece la autoexpresión cuando su gente está emancipada de la autoridad y es capaz de demandar y defender su autonomía y libertad de elección. En contraste, una sociedad está sesgada hacia valores de supervivencia cuando sus integrantes están más preocupados por las vicisitudes de un entorno incierto y por no tener las necesidades básicas garantizadas.

El resto del artículo se estructura de la siguiente manera. En la sección I se presentan referencias a la bibliografía que son útiles para construir los mecanismos sociales de una teoría cultural del desempeño político/económico. En la sección II se elabora un modelo formal que combina herramientas de la teoría de juegos evolutivos con un análisis de comportamiento estratégico en el que se emplea una heurística secuencial como concepto de solución. En la sección III se presenta una solución gráfica del modelo en donde la propagación de una actitud participativa da pauta a una reforma institucional una vez que se cruzan ciertos umbrales culturales. En la sección IV se construye un escenario en el que el statu quo no logra ser sustituido directamente por un régimen progresista, sino que es necesario transitar por un periodo de enfrentamientos que rebasan la negociación pacífica. Finalmente, el trabajo termina con las conclusiones y sugerencias para investigaciones futuras.

\section{LA COEVOLUCIÓN DE LA CULTURA Y EL DESEMPEÑO ECONÓMICO/POLÍTICO}

Tradicionalmente, sociólogos, psicólogos sociales, historiadores y politólogos han sido más receptivos que los economistas a la idea de que los valores culturales afectan el desempeño de una sociedad y viceversa. En particular, la agenda de 
investigación de sociólogos como Bourdieu (1986), Coleman (1988) y Putnam (1993) se mueve en las coordenadas correctas cuando vinculan las redes sociales con el desempeño de una comunidad. De esta manera, la bibliografía de capital social subraya que la pertenencia a asociaciones voluntarias y la confianza interpersonal son críticas para producir resultados cívicos, como lo son la democracia y el respeto a los derechos de propiedad. No obstante, y como lo apuntan Welzel, Inglehart y Deutsch (2005), esta premisa conduce a preguntar ¿qué tipo de lazos y normas sociales se requieren para producir una acción colectiva? Por ello, sugieren que los valores de autoexpresión son decisivos para que la sociedad civil participe en acciones-cuestionadoras-de-élites. Acciones que reflejan la capacidad de la sociedad para desarrollar instituciones promotoras de las libertades individuales y el bienestar de las mayorías.

\section{Las teorías de modernización}

La versión tradicional de la teoría de modernización acentúa el papel que tiene el desempeño socioeconómico como factor causal de la democratización de un país, el cual se manifiesta a partir de la movilización de recursos materiales para la acción colectiva (Lipset, 1959). En esta perspectiva, se argumenta que la industrialización, el mayor acceso a la información, la creciente complejidad social y el incremento en los niveles de ingreso y educación contribuyen a mejorar las capacidades materiales de los individuos que son necesarias para actuar en función de sus propias decisiones. En contraste, la versión más reciente de esta teoría tiene un componente cultural en la medida en que plantea que el desarrollo socioeconómico no sólo mejora las capacidades materiales del individuo (financieras, físicas e intelectuales), sino también las actitudes mentales conducentes a proteger la libertad de elegir (Welzel, Inglehart y Klingemann, 2003; Inglehart y Welzel, 2005).

La versión cultural de la teoría de modernización hace referencia a una "secuencia del desarrollo humano" en la que las sociedades experimentan una transformación no lineal de los valores culturales como resultado de transitar por diferentes etapas socioeconómicas. Una sociedad se mueve de valores tradicionales a seculares cuando se urbaniza y la actividad industrial se torna más relevante que la actividad agrícola; posteriormente, se mueve de valores de supervivencia a la autoexpresión cuando el sector servicios adquiere preponderancia. ${ }^{1}$ Por tan-

\footnotetext{
${ }^{1}$ Estos dos indicadores culturales son creados mediante la técnica de componentes principales. Los valores tradicionales acentúan los siguientes cinco factores (lo contrario ocurre para los
} 
to, una vez que un país cruza un cierto umbral de un índice de autoexpresión, la sociedad civil empoderada adquiere la capacidad para demandar los derechos políticos y civiles conducentes a la democracia. En síntesis, estos autores subrayan un vínculo causal que va del desempeño socioeconómico a los cambios culturales (vínculo medio-motivaciones) y otro que va de los valores culturales al desempeño político (vínculo motivaciones-reglas).

La evidencia econométrica aportada por Inglehart y Welzel (2005) sobre su teoría no ofrece una explicación de cómo las trayectorias de desarrollo económico se establecen en cada país, por lo que dejan a un lado la posibilidad de analizar un proceso coevolutivo entre variables endógenas de distintas arenas (sociocultural, económica y política). A pesar de la ausencia de pruebas econométricas relevantes, la argumentación de estos autores y su evidencia parcial es muy ilustrativa para identificar mecanismos sociales que pueden estar presentes en un modelo formal que vincule a la cultura con las acciones colectivas y las reformas institucionales.

Entre los mecanismos de la "secuencia humana del desarrollo" a integrar en el planteamiento teórico destacan los siguientes: $i$ ) un legado histórico que condiciona la naturaleza de la evolución cultural; ii) recursos socioeconómicos que inciden en las transformaciones culturales, y iii) un atributo cultural (valores de autoexpresión) que tiene que ser superado para producir un cambio discreto en una variable institucional (por ejemplo, democratización). Por otra parte, el modelo debe ser capaz de explicar cómo estos mecanismos reproducen la siguiente evidencia empírica: $i v$ ) una elevada correlación entre la posición de un país en un mapa cultural y su desempeño económico (medido en términos de ingreso per capita), y v) una alta correlación entre los valores de autoexpresión e indicadores de las capacidades de un país para resolver problemas de acción colectiva, entre las que se encontrarían las acciones-cuestionadoras-de-élites.

valores seculares): dios es muy importante en la vida del encuestado; éste suele opinar que es más importante que un niño aprenda la obediencia y la fe religiosa que la independencia y la determinación; el aborto nunca es justificable; el encuestado tiene un fuerte sentido de orgullo nacional; el encuestado favorece el respeto a las autoridades. Los valores de supervivencia subrayan los siguientes cinco factores (lo opuesto ocurre para los valores de autoexpresión): el encuestado da prioridad a la seguridad económica y física sobre la autoexpresión y la calidad de vida; el encuestado se describe como no muy feliz; la homosexualidad nunca es justificable; el encuestado nunca ha firmado una petición y no lo piensa hacer en el futuro opina que uno debe ser muy cuidadoso cuando se trata de confiar en la gente. Para mayores detalles, véase Inglehart y Welzel (2005, cap. 2). 


\section{Factores subyacentes de coevolución: la historia importa}

En el corto y mediano plazo es posible especificar mecanismos causales entre diferentes variables agregadas, pero más que hablar de causalidad resulta conveniente plantear que estas variables coevolucionan bajo una perspectiva de largo plazo. Lo anterior se desprende de estudios de corte transversal entre países que muestran que muchas de estas variables (por ejemplo, escolaridad, desarrollo institucional, ingreso per capita, innovación tecnológica, desarrollo financiero, corrupción, razón de inversión, valores culturales) están fuertemente correlacionadas entre sí (Sala-i-Martín, 1997), lo que conduce a pensar que todas ellas pueden estar vinculadas con algún legado histórico. En esta misma dirección apuntan diferentes estudios que presentan una relación estadísticamente significativa entre indicadores del desempeño agregado de países y factores geográficos o históricos.

Por ejemplo: $i$ ) variables geográficas relacionadas al entorno ecológico del país y su accesibilidad a vías marítimas y fluviales (Sachs, 2003; Blum, 2003); ii) el origen legal del país y la manera en que sus instituciones legales fueron establecidas (La Porta, López-de-Silanes y Shleifer, 2008; Berkowitz, Pistor y Richard, 2001); iii) la dotación de recursos naturales y la viabilidad de diferentes tecnologías (Engerman y Sokoloff, 1997 y 2005; Esaterly y Levine, 2002); iv) el marco institucional a partir de la colonización, la independencia o de un evento crítico del pasado distante (Acemoglu, Johnson y Robinson, 2001 y 2002); v) antecedentes religiosos (Grier, 1997; Blum y Dudley, 2001; Barro y McCleary, 2003); vi) fragmentación étnica (Easterly y Levine, 1997; Alesina y La Ferrara, 2004), y vii) proximidad geográfica y densidad poblacional (Frankel y Romer, 1999; Frankel, Romer y Cyrus, 1996).

En términos formales se puede decir que un sistema socioeconómico es coevolutivo cuando las siguientes condiciones se cumplen: $a$ ) existe una relación sistémica entre un conjunto de variables endógenas y un conjunto de factores subyacentes de coevolución (UFC, por sus siglas en inglés); $b$ ) estas variables endógenas continuamente se están realimentando a partir de un proceso sincrónico o bien exhiben un mecanismo de causalidad bidireccional (cumulative causation). En el último escenario, los comovimientos de las variables son resultado de un proceso diacrónico entre patrones emergentes y el entorno social (realimentación de baja frecuencia); c) la dinámica de este proceso se explica a partir de un esquema evolucionista.

En consecuencia, la presencia de coevolución implica que no siempre es factible distinguir una dirección de causalidad entre dos variables endógenas con 
datos de alta frecuencia (por ejemplo años, décadas), a pesar de que existe una relación sistémica entre ellas. En otras palabras, los UFC condicionan la naturaleza de la relación entre variables agregadas en términos de sus niveles promedio contemporáneos (o cualquier otra propiedad estocástica), lo cual explica la fuerte correlación observada en estudios de corte transversal.

Por tanto, los UFC son los parámetros exógenos y las condiciones iniciales de variables endógenas de un proceso sincrónico/diacrónico que hace posible la existencia de trayectorias de desarrollo diferenciado para un conjunto de regiones o países. La naturaleza de estos factores se determina en términos de consideraciones geográficas o episodios críticos de la historia. Ejemplos de estos episodios son las etapas iniciales de una colonización, el colapso del feudalismo, el inicio de un periodo independiente, la revolución industrial, la Ilustración, la aparición de diferentes religiones, el establecimiento de un sistema de planeación centralizado, o cualquier otra perturbación de carácter ideológico. Mientras que los parámetros exógenos mantienen una influencia directa sobre los patrones emergentes contemporáneos, la influencia de las condiciones iniciales es sólo indirecta ya que el valor de las variables endógenas se va modificando a lo largo del proceso evolutivo. Por ello cuando se construye un modelo para analizar las trayectorias de desarrollo es muy importante especificar qué parámetros adoptan un valor definido en el pasado remoto y qué variables se consideran fijas por razones de manejo analítico.

La evidencia presentada en las referencias anteriores no es suficiente para identificar la manera en que los factores geográficos y la historia afectan el desempeño económico; no obstante, estos hechos constituyen un primer paso en el planteamiento de una teoría en la que los UFC explican los diferentes clubes de desarrollo observados en los datos (Quah, 1997). Un candidato plausible para estos UFC es el concepto de zonas culturales desarrollado por Huntington (1996). Este mapa cultural se traza a partir de datos de la Encuesta Mundial de Valores (WVs) en la que las coordenadas de los diferentes países se definen a partir de su posición en el eje vertical de valores tradicionales/seculares y en el eje horizontal de valores de supervivencia/autoexpresión (Inglehart, 1997).

Aunque existe cierta subjetividad al clasificar a alguno de estos países en una zona cultural específica, es importante resaltar que al interior de una zona cultural los países tienen valores culturales muy similares. Si bien estos valores se miden con datos contemporáneos, la definición de la zona cultural está relacionada con la tradición religiosa de los países, su pasado colonial o su proximidad geográfica (ex comunistas, Europa católica, confucionistas, Europa protes- 
tante, angloparlantes, América Latina, sur de Asia, África). Cabe notar que los individuos en las sociedades afluentes tienden a enfatizar valores seculares y la autoexpresión, mientras que las sociedades pobres están compuestas por individuos que son predominantemente tradicionales y preocupados por su seguridad material. En el caso de países de ingresos medios, los valores seculares y de autoexpresión se encuentran en niveles intermedios o bien estos indicadores se presentan con una combinación de valores en los extremos opuestos. La fuerte correlación observada entre el mapa cultural y el desempeño económico de los países es un prerrequisito para avalar la coevolución entre estos dos tipos de variables.

En línea con la teoría coevolutiva de este texto, Acemoglu et al. (2007) argumentan que la fuerte correlación de corte transversal observada en variables contemporáneas de las arenas política y económica se debe a condiciones establecidas en un pasado remoto. Estas condiciones hicieron posible que los países se embarcaran en diferentes trayectorias de desarrollo. Para estos autores, existen episodios críticos, tan lejanos como 500 años atrás, que pueden ser identificados como las condiciones iniciales de estas trayectorias. Estos autores muestran que cuando algunos de estos UFC se introducen como variable de control en un estudio panel de ingreso per capita y democracia, la relación estadística entre estas variables contemporáneas desaparece. Asimismo, la variabilidad de los coeficientes fijos se explica de manera satisfactoria a partir de factores históricos. Estos resultados no deben interpretarse como la falta de asociación entre el ingreso y el grado de democracia; más bien avalan la hipótesis de que la relación entre ellas es de largo plazo, al ser variables endógenas que evolucionan conjuntamente. Es decir, una vez que las sociedades se mueven a lo largo de su trayectoria de desarrollo correspondiente, los países ricos tienden a ser más democráticos y los países con regímenes autoritarios tienden a ser más pobres.

Para probar formalmente la coevolución entre variables endógenas y la relevancia de ciertos factores históricos en la formación de trayectorias de desarrollo es necesario implantar técnicas econométricas específicas. No obstante, la evidencia preliminar disponible es congruente con una teoría en donde las instituciones y el desempeño político-económico son influidos por la cultura prevaleciente, y en donde las trayectorias de las variables endógenas se asocian en el largo plazo con el legado histórico de cada país o región. Sin embargo, es conveniente aclarar que el condicionamiento cultural no debe confundirse con una posición de determinismo cultural. La evidencia histórica muestra que es posible encontrar procesos de reversión de fortunas, de tal forma que un país puede mo- 
verse de una trampa de pobreza a una trayectoria de ingresos altos o medios (Corea del Sur, Singapur, Botsuana) o viceversa (por ejemplo, Argentina).

\section{UN MODELO EVOLUTIVO CON RACIONALIDAD ACOTADA}

En esta sección se construye un modelo para analizar la manera en que la cultura se transforma a partir del tiempo y cómo ésta afecta el grado de cohesión de la sociedad civil. Aunque en cada etapa del juego las élites y los miembros participativos de la sociedad civil llevan a cabo planteamientos estratégicos para definir el marco institucional, el elemento crítico para determinar la fuerza de la acción colectiva tiene que ver con el tamaño que presenta este segmento de la sociedad civil. En otras palabras, el grado de cohesión o la acción coordinada de la sociedad civil depende del número de individuos en la población que comparten una disposición a defender sus derechos.

Conviene acentuar que el modelo no pretende capturar los detalles de la mecánica del crecimiento económico, ni tampoco diferenciar los efectos de las instituciones políticas y económicas. Más bien el objetivo es identificar las condiciones culturales que se requieren para que una sociedad se mueva del statu $q u o$, caracterizado por un ingreso per capita bajo e instituciones extractivas, a un régimen progresivo en el que el ingreso es elevado y las élites se adhieren al marco legal. En otras palabras, el modelo plantea un proceso dinámico en el que la cultura sigue diferentes trayectorias para establecerse en uno de estos dos regímenes institucionales. Por otra parte, el modelo también permite generar un periodo de transición caracterizado por disputas desbordadas, en el que la sociedad civil cruza los límites tolerados por las élites y éstas, en consecuencia, responden con represiones y frenando cualquier tipo de reforma institucional. ${ }^{2}$

\section{Actores, regímenes institucionales y fuerza negociadora}

Este modelo evolutivo se conforma por una secuencia de juegos en los que las élites y una sociedad civil dividida son los principales actores. En el componente de toma-de-decisiones del modelo, las élites y la coalición de los miembros participativos de la población negocian el régimen institucional a partir de conjeturas heurísticas en cada etapa del juego. En el componente de aprendizaje social

\footnotetext{
${ }^{2}$ Tilly (2004) presenta diversos episodios de esta forma de disputa en la transición hacia la democracia.
} 
del modelo, los beneficios diferenciales de una ecuación de reproducción determinan la tasa de difusión de las variantes culturales y, por ende, el número de individuos de la población que están dispuestos a negociar con las élites. De esta manera, se dice que el cemento de la sociedad civil es resistente cuando una actitud participativa prevalece en la mayoría de la población.

En este juego de dos-personas se supone que las élites forman un grupo compacto compuesto por un número reducido de individuos que actúan concertadamente en sus acciones de gobierno. En otras palabras, las élites son los actores encargados de diseñar y aplicar la ley, por lo que tienen la capacidad de extraer rentas de las actividades productivas cuando las instituciones son débiles. Asimismo, las élites controlan el aparato estatal y tienen información privilegiada que les permite conocer, por adelantado, los movimientos de los miembros de la sociedad civil. Esta asimetría en la información les confiere ventajas estratégicas cuando toman decisiones sobre la manera en que hacen valer el orden establecido.

Los actores que componen la sociedad civil son individuos con diferentes variantes de un atributo cultural (o actitudes), los cuales tienen la obligación de seguir las reglas establecidas por las élites. Los miembros de la sociedad civil con una actitud participativa (o contraélites) tienen una motivación para impulsar su agenda en la negociación de las instituciones (o políticas públicas), mientras que los miembros conformistas son reticentes a usar la negociación para alterar las instituciones prevalecientes, por lo que aceptan pasivamente las reglas del gobierno y la proporción del ingreso que las élites les han asignado.

Cuando la actitud participativa es generalizada, la sociedad civil tiene la fuerza suficiente para fracturar el statu quo y empujar a las élites hacia una reforma institucional. En este nuevo escenario, la ley tiene validez universal y, por ello, se presume que la distribución del ingreso mejora y la economía se vuelve más productiva. Por otra parte, la fragmentación cultural de la población crea cierta rivalidad entre los individuos con los dos tipos de variantes (participativos y conformistas). Los costos de la fragmentación pueden ser interpretados como los costos, económicos o psicológicos, en que incurre un individuo por ser miembro minoritario de la sociedad.

Los diferentes regímenes institucionales, acciones, beneficios y fuerzas negociadoras son representados a partir del juego en forma normal descrito en la figura $1 .^{3}$ Las élites (E) pueden escoger entre dos posibles acciones: "respetar" o

\footnotetext{
${ }^{3}$ En términos formales, un proceso de negociación se caracteriza por una secuencia de ofertas y contraofertas; sin embargo, bajo el esquema de un juego no cooperativo la fuerza de negociación
} 
Figura 1. Regímenes institucionales y acciones

\begin{tabular}{|c|c|c|c|}
\hline \multirow{4}{*}{ élites } & \multirow[b]{3}{*}{ respetar } & \multicolumn{2}{|c|}{ PM } \\
\hline & & cumplir & movilizarse \\
\hline & & $\begin{array}{r}B_{e}(1-\mathrm{x}), B_{S} x-\gamma(1-x) \\
\text { tecnocrático }\end{array}$ & $\begin{aligned} R, H-\gamma(1-x) & \\
& \text { progresivo }\end{aligned}$ \\
\hline & abusar & $\begin{array}{r}R+\tau L x, \mathrm{~L}(1-\tau)-\gamma(1-x) \\
\text { statu quo }\end{array}$ & $\begin{array}{r}B_{e}(1-x), B_{S} x-\gamma(1-x) \\
\text { disputado }\end{array}$ \\
\hline
\end{tabular}

"abusar" de los derechos civiles y políticos del público en general, mientras que los miembros participativos (PM) pueden "cumplir" con las leyes y políticas públicas aun cuando provengan de instituciones extractivas, o bien "movilizarse" en un intento por crear instituciones que sean más democráticas. ${ }^{4}$ Esta caracterización da lugar a cuatro regímenes teóricos (statu quo, progresivo, disputado y tecnocrático), pero sólo tres de ellos tienen relevancia empírica.

En la actualidad muchos países en el mundo presentan instituciones extractivas que son producto de élites abusivas y ciudadanos pasivos (régimen de statu quo), otros son gobernados mediante instituciones no extractivas en donde las élites se conducen legalmente y sus ciudadanos están listos para movilizarse y defender sus derechos (régimen progresivo), y un tercer grupo más pequeño que experimenta un periodo de transición en el que los PM se movilizan, protestan y boicotean al mismo tiempo que las élites usan la represión en un intento por sostener las instituciones extractivas (régimen disputado). En contraste, no es común observar países en donde los miembros de la sociedad civil tienen una actitud permisiva mientras que las élites están dispuestas a reducir sus privilegios y respetar los derechos individuales. Este escenario requeriría de una tecno-

se refiere a la idea de que existen asimetrías estratégicas entre los jugadores que pueden inclinar la solución del juego hacia un equilibrio particular.

${ }^{4}$ Cuando las instituciones son extractivas los derechos de propiedad no están bien protegidos, por lo que las élites pueden implantar diferentes acciones para extraer rentas del esfuerzo y los recursos de los ciudadanos. En contraste, las instituciones no extractivas (o democráticas) buscan emparejar las condiciones en las que se desarrollan los individuos y establecer mecanismos de mercado y de negociación política que no estén sesgados a favor de las élites. Para mayores detalles sobre estos conceptos ver Acemoglu y Johnson (2005) y North (1981). 
cracia ilustrada y benevolente con la disposición de promover instituciones conducentes al bienestar de las mayorías (régimen tecnocrático).

Sin embargo, las acciones que tienen el potencial de producir el régimen tecnocrático no son neutrales en el modelo. Éstas juegan un papel importante en el planteamiento estratégico, ya que los beneficios obtenidos bajo este régimen y el disputado le confieren a E y PM su fuerza negociadora. Por tanto, y siguiendo a Knight (1992), estos beneficios pueden ser interpretados como los beneficios de ruptura recibidos por cada una de estas coaliciones en caso de que no se alcance un acuerdo en la negociación y diseño de instituciones. En esta formulación, el acuerdo que lleva al statu quo es preferido por las élites mientras que el acuerdo que conduce al régimen progresivo es preferido por los miembros participativos. En consecuencia, cuando el parámetro $B_{e}$ de los beneficios de ruptura es relativamente grande, las élites no tienen el incentivo para respaldar las instituciones negociadas bajo el statu quo o el régimen progresivo; de igual forma, cuando el parámetro $B_{s}$ es relativamente grande, los PM son renuentes a obedecer los acuerdos. En el modelo se supone que los beneficios en los regímenes tecnocrático y disputado son idénticos para simplificar la manipulación algebraica. En cualquier caso, la realización del escenario tecnocrático puede ser descartada para valores específicos de los parámetros.

Cabe aclarar que los beneficios del jugador-columna corresponden a un actor representativo de los miembros participativos de la sociedad civil (PM), mientras que los beneficios del jugador-renglón corresponden a las élites que actúan como un grupo consolidado. Por ello, el modelo supone que al interior del grupo conformado por los PM los individuos son homogéneos y, por ello, deciden simultáneamente si cumplir o movilizarse. Este supuesto simplificador no genera un escenario, poco realista, en el que todos los miembros de la sociedad civil son manifestantes activos. Esto es así ya que la presencia de conformistas en el modelo permite la generación de un patrón más apegado a la realidad histórica, en la que solamente un subconjunto de la sociedad civil se moviliza. Detrás de este juego de dos personas existe un problema de acción colectiva para la sociedad civil, ya que la decisión del PM representativo depende del porcentaje de individuos que exhiben una actitud participativa, número que se determina en un proceso dinámico, como se explicará posteriormente.

Los beneficios en los cuatro regímenes dependen del número de miembros de la sociedad civil que tienen valores participativos, número que al ser estandarizado se define como $x_{t} \varepsilon(0,1)$. Esta variable mide el grado de cohesión de la sociedad civil e incide en su fuerza negociadora vis à vis con las élites, en 
los costos de fragmentación y en la cantidad de recursos extraídos por las élites. Bajo el statu quo, los PM cumplen con un orden abusivo en el que una fracción $(\tau<1)$ del ingreso productivo $(L)$ de cada individuo es extraído y, por ende, las élites obtienen un total de $\tau L x$ recursos adicionales a los $R$ que obtienen en un escenario en el que las instituciones protegen los derechos de propiedad. ${ }^{5}$ Por sencillez, estos ingresos son extraídos exclusivamente de los PM puesto que son los miembros más productivos de la sociedad. Por otra parte, los ingresos de los conformistas (CM) son definidos como $C-\gamma x$ con $C<L$. Los costos de fragmentación están representados en el segundo término de esta expresión y de la expresión que describe los ingresos de los PM. Por lo tanto, entre mayor sea el número de miembros participativos, mayor (menor) será el costo que los conformistas (participativos) pagan por ser una minoría (mayoría).

En el régimen progresivo, los derechos están protegidos y las instituciones son capaces de crear los incentivos adecuados. De esta manera la productividad de los PM se incrementa para alcanzar un ingreso de $H>L$, en tanto que las élites sólo pueden obtener el nivel de ingresos $(R)$ que es viable cuando reina el imperio de la ley. En los regímenes tecnocrático y disputado los ingresos netos describen los beneficios bajo ruptura, por lo que entre más cohesionada se encuentre la sociedad civil (mayor sea $x$ ), más débil es la fuerza relativa de las élites. En otras palabras, $B_{e}(1-x)$ y $B_{s} x$ son parte de los beneficios de las élites y los PM, respectivamente. Cabe notar que los beneficios de la sociedad civil en estos dos regímenes incorporan un término para los costos de fragmentación. De los valores presentados en las celdas de la figura 1 se observa que el ingreso nacional (suma de los beneficios para E, PM y CM) en el statu quo $\left(Y^{s q}\right)$ es menor que el ingreso obtenido en el régimen progresivo $\left(Y^{p r}\right)$, como se aprecia en la siguiente expresión:

$$
Y^{s q}-Y^{p r}=(L-H) x<0 .
$$

Esta expresión muestra que la diferencia entre los dos regímenes está relacionada con la baja productividad de los miembros participativos en el statu quo. La brecha se incrementa con el número de PM y, por ello, el grado de cohesión de la sociedad determina qué tan grande es el potencial que tiene una reforma institucional para mejorar el ingreso nacional.

\footnotetext{
${ }^{5}$ Nótese que la extracción total de las élites se calcula multiplicando la cantidad extraída a cada participante por el valor de $x$.
} 


\section{Conjeturas, información asimétrica y toma-de-decisiones}

Una vez que los diferentes regímenes y sus beneficios han sido definidos, el siguiente paso consiste en determinar bajo qué condiciones se puede dar una reforma institucional que mueva a la sociedad del statu quo al régimen progresivo. El tipo de régimen prevaleciente está estrechamente vinculado con la naturaleza de las conjeturas adoptadas por los PM respecto a los movimientos de las élites que, por su parte, son conscientes de las acciones de la sociedad civil. En caso de suponer hiperracionalidad, el problema descrito en la matriz de beneficios de la figura 1 se puede resolver a partir de la teoría de juegos clásica y el concepto de solución de equilibrio Nash (NE). Por tanto, después de unos pasos algebraicos sencillos es fácil mostrar que el statu quo y el régimen progresivo son NE cuando las siguientes condiciones se cumplen:

$$
R>B_{e}, L(1-\tau)>B_{s} \text { y } H>L
$$

Mientras que la última desigualdad se cumple por definición, las otras dos tienen que ser impuestas si se quiere descartar las desviaciones unilaterales del régimen progresivo y del statu quo. Si bien estas condiciones no dependen del grado de cohesión de la sociedad, estos dos regímenes también pueden ser establecidos como NE a partir de condiciones más débiles que sí dependen del valor de $x$. No obstante, en el modelo de este artículo no se contempla el uso de la teoría de juegos clásica sino, más bien, se supone que los jugadores presentan racionalidad acotada y asimetrías en la información, de tal forma que se aplica un concepto de solución secuencial. Con reglas heurísticas secuenciales la toma-dedecisión para cada jugador se aplica en un orden específico, en el que el jugador que cuenta con ventajas informativas, que en este caso son las élites, actúa hasta el final.

Bajo el criterio de decisiones heurísticas, los PM seleccionan una estrategia pura (es decir, con probabilidad uno) basados en una conjetura de qué tan probable es que las élites adopten una postura abusiva. Las élites, conscientes de este comportamiento, saben con certidumbre los movimientos de los PM y seleccionan la acción que más les conviene. En otras palabras, este concepto de solución descarta el supuesto de "conocimiento común" en el que cada jugador es racional, sabe que el otro es racional, sabe que el otro jugador es consciente de ello y así sucesivamente. Asimismo, el concepto de solución aquí descrito no requiere que las élites observen las acciones de los PM antes de llevar a cabo su 
movimiento, basta con suponer que son conscientes de las conjeturas de los PM $\mathrm{y}$, por ende, las acciones pueden ser adoptadas simultáneamente a pesar de que las decisiones sean tomadas secuencialmente.

En concreto, se supone que los PM calculan la probabilidad "umbral" $(p)$ de que las élites sean abusivas, la cual corresponde al escenario en el que los PM son indiferentes entre "cumplir" o "movilizarse". Posteriormente, esta probabilidad se compara con una señal exógena o probabilidad subjetiva $(q)$ de los miembros participativos sobre la posibilidad de que las élites abusen contra los derechos civiles y políticos. En consecuencia, cuando la conjetura de los PM es que $q>p$ ellos creen que las élites reprimirán cualquier tipo de protesta o boicot de la sociedad civil; en contraste, cuando su conjetura es que $q \leq p$ ellos creen que las élites serán respetuosas.

Dado que los PM son racionales y prefieren obtener los beneficios más altos posibles, seleccionarán "cumplir" si $q>p$ y las condiciones (2) son válidas; pero optarán por "movilizarse" cuando estas condiciones se cumplan y $q \leq p$. Es decir, cuando los PM creen que las élites no serán abusivas se movilizarán en un intento por promover una reforma institucional, pero permanecerán pasivas si su conjetura es que las élites serán represivas. Por otra parte, las élites son conscientes de los valores $(q, p)$ y si PM cumplirá o se movilizará. Bajos estas circunstancias, es fácil mostrar que las élites racionales validarán las conjeturas de los PM.

La señal $q$ está basada en la experiencia y la interpretación de los PM sobre cómo las élites y sus instituciones han operado en el pasado. Este valor puede derivar, por ejemplo, de indicadores del grado de corrupción, del estado de derecho, o de acciones específicas adoptadas por las élites que son transmitidas a partir de redes sociales; en consecuencia, cuando $q$ tiende a cero la señal es que la calidad institucional es muy alta. En este artículo, la calidad institucional se supone exógenamente dada, por lo que un modelo más sofisticado tendría que replantear esta situación. No obstante, si esta señal se modifica sólo cuando existen cambios drásticos en el entorno institucional y existe una retroalimentación positiva entre el desempeño contemporáneo y la señal, entonces, el valor fijo de este parámetro es neutral a los resultados.

De manera similar a la formulación de la teoría de juegos clásica, el statu quo y el régimen progresivo son los únicos dos equilibrios posibles bajo las condiciones (2). Sin embargo, con la solución de heurísticas secuenciales el modelo puede identificar cuál de estos equilibrios es el que a fin de cuentas prevalece una vez que los valores del vector $(q, p)$ son definidos, en donde la función de probabilidad $p$ viene dada por la siguiente expresión: 


$$
p=\frac{B_{s} x-H}{2 B_{s} x-H-L(1-\tau)}
$$

con $0<p \leq 1$ ya que $x,(1-\tau)<1$ y las condiciones (2) son válidas.

Nótese que la probabilidad $p$ obtenida cuando se igualan los valores medios de los beneficios de las distintas acciones de los PM es una función de la cultura de la sociedad $(x)$. De esta expresión, es fácil probar que estas dos variables están positivamente relacionadas a partir de una curva convexa. Para valores de $p(x) \varepsilon(0, q)$ las decisiones heurísticas de las élites y los PM llevan al statu $q u o$, mientras que para $p(x) \varepsilon(q, 1)$ ambos actores prefieren reformar las instituciones y establecer un régimen progresivo. Por tanto, cuando el número de miembros de la sociedad civil que activamente promueven la agenda institucional se incrementa y el valor de $p$ sobrepasa a $q$, la conjetura de PM se modifica al aparecer la creencia de que las élites no abusarán contra los derechos civiles y políticos. En consecuencia, los problemas de acción colectiva se pueden resolver cuando prevalece una cultura de participación; es decir, la acción coordinada de la sociedad civil debilita la posición estratégica de las élites y hace factible que se adopte una reforma institucional progresiva.

\section{La evolución de la actitud participativa}

Aunque el conjunto de miembros participativos es homogéneo, la sociedad civil también se constituye con individuos del tipo conformista. La composición del atributo cultural en la sociedad está relacionada con la experiencia social y, en particular, con los beneficios relativos que cada variante obtiene en los periodos previos. Atendiendo a que el cambio cultural no es solamente producto del conocimiento y de factores cognitivos, aquí se plantea que la propagación de una variante es resultado de la experiencia. De esta concepción se desprende que la cultura puede ser vista como una variable reversible, como lo sugieren Inglehart y Welzel (2005).

Debido a las rigideces en la información se supone que los efectos demostrativos son muy lentos y, por ello, sólo una fracción de la población es capaz de modificar sus actitudes en cada periodo a pesar de que un comportamiento en específico sea claramente ganador. Para describir los cambios en las proporciones de las variantes culturales se emplea la dinámica de duplicación desarrollada en la teoría de juegos evolutivos. Asimismo, los beneficios de los conformistas $\left(\Pi^{C M}\right)$ no dependen de la toma-de-decisiones secuenciales, mientras que 
los beneficios observados por los miembros participativos $\left(\Pi^{P M}\right)$ varían en términos de la combinación de probabilidades $(p, q) \mathrm{y}$, por ende, del régimen establecido (statu quo o progresivo). Por tanto, los beneficios de los diferentes miembros de la sociedad civil (PM y CM) están dados por las siguientes expresiones:

$\Pi_{C}^{P M}=L(1-\tau)-\gamma(1-x)$, cuando $q>p$ y la selección es ("abusar", "cumplir")

$\Pi_{M}^{P M}=H-\gamma(1-x)$, cuando $q \leq p$ y la selección es ("respetar", movilizar")

$\Pi^{C M}=C-\gamma x$, para todos los regímenes.

Apelando a la lentitud del "contagio", sólo un porcentaje $\mu$ de los miembros de la sociedad civil tienen la posibilidad de modificar su atributo cultural en cada periodo a partir del aprendizaje social, y de este número una proporción $x$ $(1-x)$ interactúa con alguien que puede ofrecer la información necesaria sobre el diferencial de beneficios entre variantes culturales (Bowles, 2004); es decir, la información es transmitida cuando un CM y un PM son emparejados aleatoriamente. Por tanto, entre mayor sea el diferencial $\left(\Pi^{P M}-\Pi^{C M}\right)$ mayor será la posibilidad de que la actitud de CM se desvanezca con el tiempo. Estos tres factores combinados dan lugar a la dinámica evolutiva descrita con la siguiente ecuación:

$$
\frac{d x}{d t}=\mu x(1-x)\left[\Pi^{P M}-\Pi^{C M}\right]
$$

en donde $\Pi^{P M}-\Pi^{C}=\left\{\begin{array}{l}L(1-\tau)-(\gamma+C)+2 \gamma x \text { cuando } q>p \text { (statu quo) } \\ H-(\gamma+C)+2 \gamma x \quad \text { cuando } q \leq p \text { (régimen progresivo) }\end{array}\right.$

De esta ecuación de duplicación es claro que hay tres equilibrios para el atributo cultural, dos de ellos produciendo un monomorfismo: $x=0, x=1$, y otro produciendo una población culturalmente heterogénea $\left(0<x<1\right.$, tal que $\Pi^{P M}=$ $\left.\Pi^{C M}\right)$. Debido a que esta ecuación es una función-con-pasos, el diferencial de beneficios descrito en (7) varía dependiendo del tipo de régimen en que la sociedad se ubica. Las pendientes de estas líneas son idénticas y el intercepto es diferente sólo respecto al primer término, de tal forma que el intercepto bajo el statu quo es menor que bajo el régimen progresivo. Cabe notar que el diferencial de beneficios puede ser positivo o negativo, por lo que el número de miembros participa- 
tivos puede crecer o decrecer con el transcurso del tiempo. Una vez que el tamaño relativo de la variante cultural es especificado para cada periodo, los individuos con la variante participativa deciden si "cumplir" o "movilizarse" dependiendo de sus conjeturas.

En esta formulación, los costos de fragmentación (el último término del diferencial de beneficios en 7) producen líneas con pendientes positivas y, por ello, el equilibrio interior no puede ser estable; aunque con una descripción no lineal este resultado fácilmente se podría modificar. La presencia de una funcióncon-pasos y el hecho de que la función de probabilidad está positivamente relacionada con el número de PM hacen posible que, al cruzarse el umbral cultural, los individuos prefieran súbitamente terminar con el statu quo y crear instituciones no extractivas, como se estudia con más detalle en la siguiente sección. En consecuencia, el modelo es capaz de explicar cómo una modificación continua en la variable cultural puede producir un cambio discreto en el régimen institucional, como se observa en la evidencia histórica.

\section{LA DINÁMICA DE LA ACCIÓN COLECTIVA Y LA DEPENDENCIA HISTÓRICA}

El modelo evolutivo completo se describe mediante las reglas heurísticas, las dos condiciones de equilibrio (2), la función de probabilidad (3) y la ecuación de duplicación (7). La expresión (3) indica los rangos del atributo cultural (x) en donde la decisión heurística es a favor del statu quo o del régimen progresivo; es decir, identifica el bagaje cultural que hace viable a los distintos regímenes institucionales. La expresión (7) especifica la dinámica con la que se propagan las actitudes entre la población y el rango de condiciones iniciales que permiten la expansión de la variante participativa.

El modelo presenta un conjunto de parámetros positivos $\left(B_{S}, B_{e}, H, L, \gamma\right.$, $q, \tau)$ y la condición inicial de la cultura que no son explicados en el sistema evolutivo. Algunos de estos parámetros son considerados exógenos para simplificar el tratamiento matemático (el nivel de productividad en cada régimen $(H, L)$ o la señal percibida sobre la calidad institucional), mientras que otros pueden ser interpretados en términos de factores históricos de gran relevancia (por ejemplo, presiones políticas externas que afectan $B_{S}$ y $\left.B_{e}\right)$. El siguiente análisis se centra en condiciones iniciales clave (UFC o legados históricos) que dependen de eventos históricos remotos o episodios críticos que en un momento determinado produjeron las bases para la orientación de los valores de la sociedad. A partir de 
este enfoque evolutivo, la figura 2 presenta un escenario simple en el que el legado histórico no importa en el comportamiento de largo plazo de la sociedad.

Si se comienza con el legado histórico $x$, que especifica el número inicial de PM en la sociedad civil, la figura 2 muestra la manera en que esta actitud cultural se difunde con el paso del tiempo. Esta dinámica permite a la sociedad cruzar el umbral cultural $\left(x_{T}\right.$ tal que $p\left(x_{T}\right)=q$ ) en el que los actores modifican sus conjeturas y apoyan una reforma institucional. En el cuadrante inferior se observa que la expansión de $x$ afecta la probabilidad $p$, la cual se incrementa lentamente para pasar del rango definido por $p(x)<q$, en donde las conjeturas son tales que las élites y los PM favorecen el statu quo, al rango definido por $p(x) \geq q$, en donde ambos actores avalan un nuevo orden en el que operan instituciones no extractivas.

En el cuadrante superior se observa la propagación de los individuos participativos, ya que este comportamiento ofrece beneficios relativos mayores en cualquiera de los dos regímenes. Esta dinámica se describe gráficamente con la dirección de las flechas a lo largo de estas líneas (figura 2). Asimismo, este cuadrante ilustra cómo el nuevo régimen se establece de manera abrupta una vez que la acción colectiva es respaldada por un porcentaje relativamente elevado de miembros de la sociedad civil. Cabe notar que el legado histórico (esto es, la posición inicial de $x$ en el eje horizontal) sólo influye en el tiempo de adopción del

Figura 2. Convergencia hacia un régimen progresivo

$$
(L(1-\tau)>\gamma+C)
$$

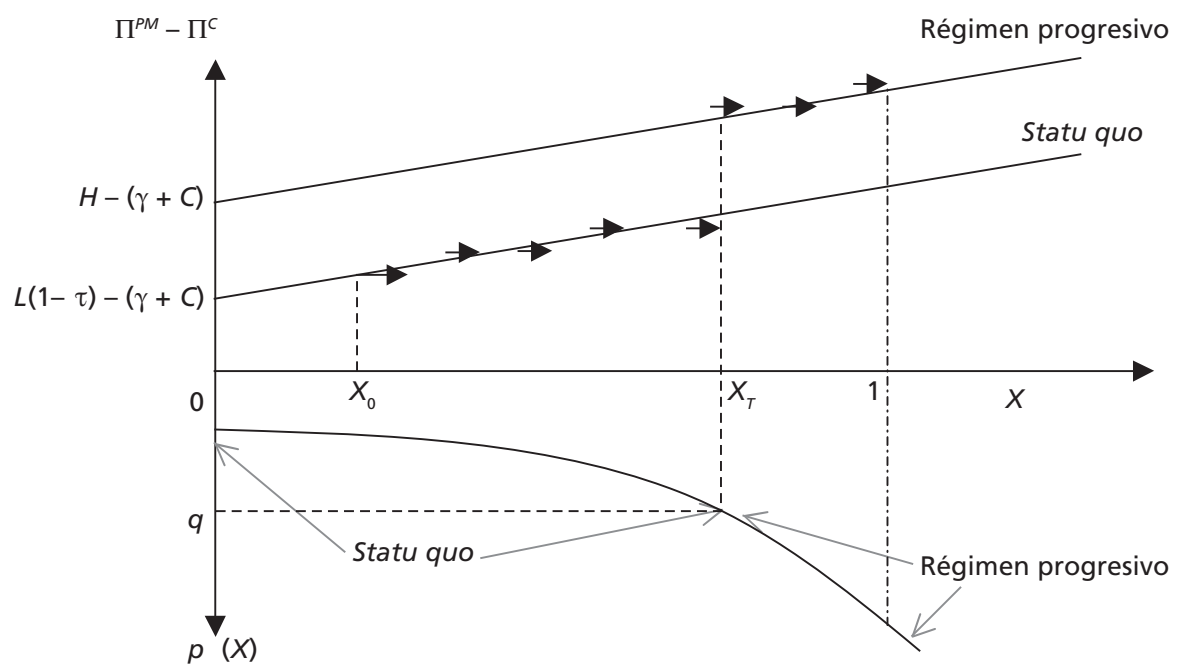


régimen progresivo ya que, al final de cuentas, todas las condiciones iniciales llevan a la misma trayectoria de ingresos altos y a una solución de esquina en donde todos los miembros de la sociedad civil son muy participativos.

El parámetro $q$ que representa la percepción de la calidad institucional, es considerado exógeno en el modelo a pesar de que se haya producido una rápida reforma institucional. Sin embargo, esta simplificación no tiene consecuencias para los resultados cuando los individuos ajustan este indicador en términos de experiencias previas. En la figura 2 se observa que al cruzarse el umbral $x_{T}$ los individuos comienzan a experimentar una mejora sostenida en el comportamiento de las élites, las cuales se ven restringidas por la ley en el nuevo entorno institucional. Esta señal podría con el tiempo inducir una reducción en el valor de $q$ (es decir, una mejora en la percepción). Diagramáticamente esto implicaría que el umbral cultural decrece (lo que no se registra en la figura 2) y, por ende, la base de atracción del régimen progresivo se incrementa. Este efecto no altera el comportamiento heurístico de los PM ni de las élites y, en consecuencia, la sociedad se sigue moviendo a lo largo de la trayectoria de altos ingresos.

\section{Inercia institucional}

La evidencia empírica muestra que, en vez de darse un proceso de convergencia, los países de todos los continentes se pueden clasificar en clubes de desarrollo. La existencia de trampas de pobreza y la disparidad en el desempeño político y económico se pueden explicar a partir de inercias institucionales. Un gran número de países se encuentran atrapados en entornos de bajo crecimiento debido a la corrupción, ineficiencias en el sistema burocrático y judicial, conculcación de los derechos civiles y políticos y, en general, por un pobre desempeño del Estado de derecho. Este tipo de inercias está presente cuando existen efectos de candado (lock-in effects) que impiden cualquier intento de reforma institucional. En el modelo que aquí se presenta, existe un candado cultural ya que no es posible adoptar instituciones progresivas cuando los individuos no desean participar en la negociación de sus propias agendas y, por tanto, los problemas de acción colectiva son severos.

En la figura 3 se presenta un escenario de inercia institucional donde el legado histórico es crítico para determinar si una sociedad pertenece a un club de alto ingreso o a uno de bajo ingreso. Para valores de $x_{0} \geq x_{T}$ el legado es tal que una sociedad puede mantener su buen desempeño histórico a partir de normas participativas que se diseminan en la población. Por lo contrario, para valores de $x_{1}<x_{T}$ 
prevalece un régimen de explotación y valores participativos que no "pagan" y, por ende, no son "contagiosos". Esta situación induce la pulverización de la sociedad y un candado cultural en el que la sociedad civil no tiene la capacidad de actuar colectivamente para romper el statu quo. En la medida en que no se produzcan factores exógenos que perturben el valor de algunos de los parámetros, este escenario da pauta a una inercia institucional y a una brecha sostenida en la disparidad de las sociedades, quedando cada una de ellas vinculada a su legado histórico.

Una de las ventajas metodológicas de este modelo evolutivo, en el que los eventos cronológicos puede ser observados, es que clarifica el porqué las inferencias derivadas de los modelos tradicionales de regresión son equivocadas cuando las variables evolucionan conjuntamente. Si se hace uso de datos contemporáneos para un país A, cuya condición inicial se ubica en $x_{0}$, y un país $\mathrm{B}$, con una condición inicial en $x_{1}$, un análisis de corte transversal mostraría una fuerte correlación entre las siguientes variables: ingreso per capita, calidad democrática, Estado de derecho (o cualquier otro indicador de desarrollo institucional) y el porcentaje de individuos que presentan valores de autoexpresión. Para A todas estas variables presentan niveles altos, mientras que para B sucede lo opuesto. De esta manera, al correr una regresión entre democracia e ingreso per capita se obtendrá un coeficiente estadísticamente significativo.

Figura 3. Candado cultural e inercia institucional

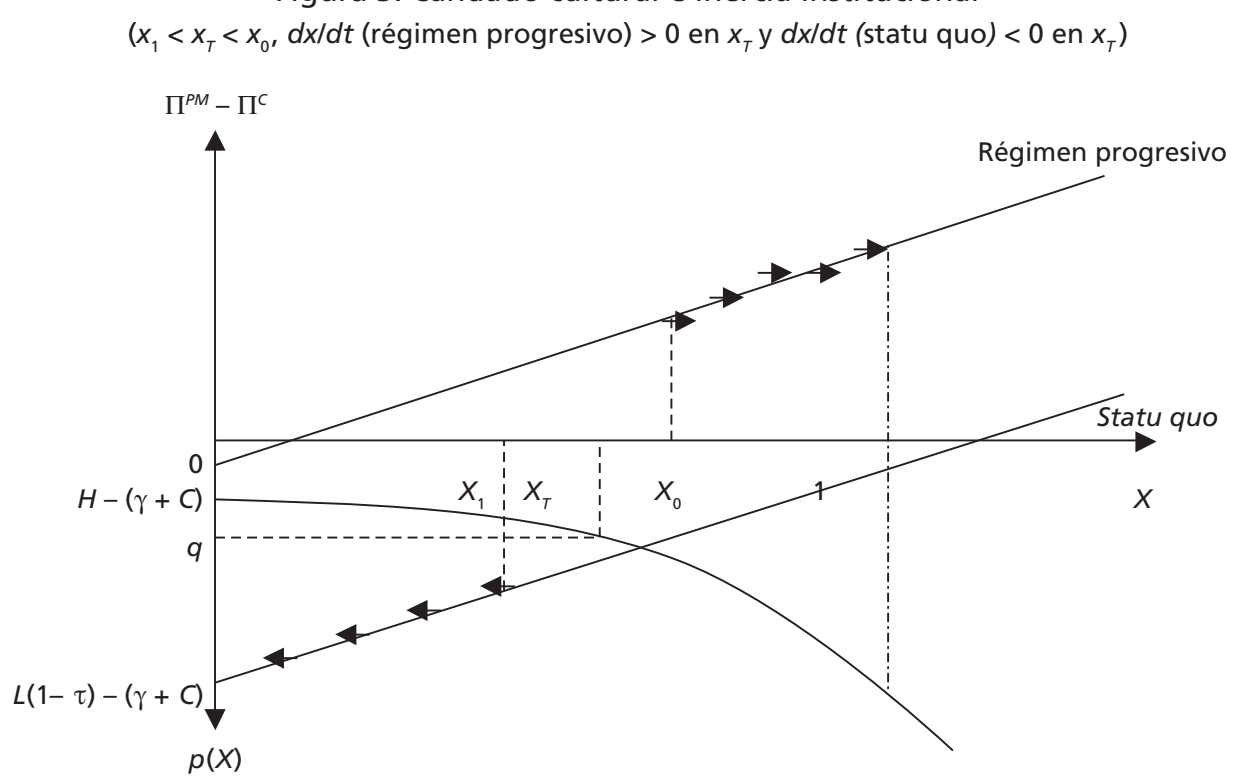


Sin embargo, si el efecto del desarrollo económico sobre la democracia se controla usando alguna variable que puede ser interpretada como el legado histórico del país o si se consideran efectos fijos para poder detectar variaciones al interior de cada país, la significancia estadística del coeficiente estimado desaparece. En un modelo con datos panel los coeficientes fijos son estadísticamente significativos ya que identifican trayectorias inferiores y superiores de desarrollo económico-político. En la figura 3 se observa que cuando un país se mueve a lo largo de su trayectoria correspondiente, no existe correlación alguna entre las variables endógenas en un periodo específico del tiempo. Esta gráfica también señala que la evidencia encontrada en el modelo de regresión panel no debe ser interpretada como una evidencia de la ausencia de conexión entre ingreso y democracia. Por construcción, se sabe que existe una asociación entre estas variables ya que ambas evolucionan conjuntamente desde una perspectiva de largo plazo. Los resultados econométricos son sólo una consecuencia de no contar en la base de datos con una muestra de casos de países en los que el umbral cultural ha sido cruzado y la reforma institucional se produce con una influencia creciente de ciudadanos participativos.

\section{Reversión de fortunas}

La bibliografía sobre desarrollo económico muestra que algunos países han sido capaces de revertir sus fortunas y moverse de un club de bajo desempeño a uno de alto desempeño (Acemoglu, 2008; Acemoglu, Johnson y Robinson, 2002). El modelo también puede explicar este tipo de escenarios para determinados rangos de los factores subyacentes de coevolución. La figura 4 presenta tres valores del UFC bajo estudio $\left(x_{0}, x_{1}\right.$ y $\left.x_{2}\right)$, los cuales dan lugar a tres trayectorias diferentes. Mientras que para $x_{1}$ la participación de los individuos declina poco a poco y el statu quo es muy robusto, para $x_{0}$ y $x_{2}$ la actitud participativa se incrementa hasta alcanzar un equilibrio en el que la población está compuesta exclusivamente por PM.

Cuando el legado está representado por $x_{0}$ existe un proceso de reversión de fortunas ya que la propagación de la variante participativa le permite a la sociedad alcanzar $x_{T}$ y moverse de un entorno de instituciones extractivas y bajo ingreso a un entorno de alta productividad e instituciones no extractivas. Por tanto, además de describir la existencia de clubes de desarrollo, este escenario muestra un cambio en la trayectoria de desarrollo para un cierto rango de valores culturales. En otras palabras, el legado histórico importa, pero ello no implica que el rezago económico de un país no pueda ser revertido endógenamente. 
En este escenario, un país con un legado histórico como $x_{1}$ no tiene la oportunidad de escapar de la trampa social en tanto que los parámetros exógenos se mantengan fijos. Sin embargo, una potencia extranjera podría perturbar el equilibrio interno al modificar los beneficios de ruptura a partir de una conquista, presión política u otros medios. Por ejemplo, si el parámetro que describe la fuerza estratégica $B_{S}$ se incrementa de tal manera que la condición (2) queda invalidada, la sociedad civil podría movilizarse y, por ende, dar pauta a un régimen de disputas desbordadas con élites abusivas, como se explica con mayor detalle en la quinta sección. Asimismo, el cambio exógeno en $B_{S}$ también modifica la función de probabilidad de acuerdo con (3) y, por ello, la curva en el cuadrante inferior se desplaza hacia abajo (situación que no se muestra en la figura 4), modificando el rango en el que prevalecen las distintas conjeturas de los PM.

En relación con los ejercicios econométricos, el efecto de la cultura sobre el régimen institucional puede ser capturado estadísticamente si el modelo panel se estima con una muestra que incluya países tipo A y B, como los descritos en el apartado anterior, y países tipo $\mathrm{C}$, en los que haya ocurrido una reversión de fortunas en algún punto del periodo muestral. En estas circunstancias, los efectos fijos serán significativos por la existencia de diferentes legados históricos

Figura 4. Reversión de fortunas

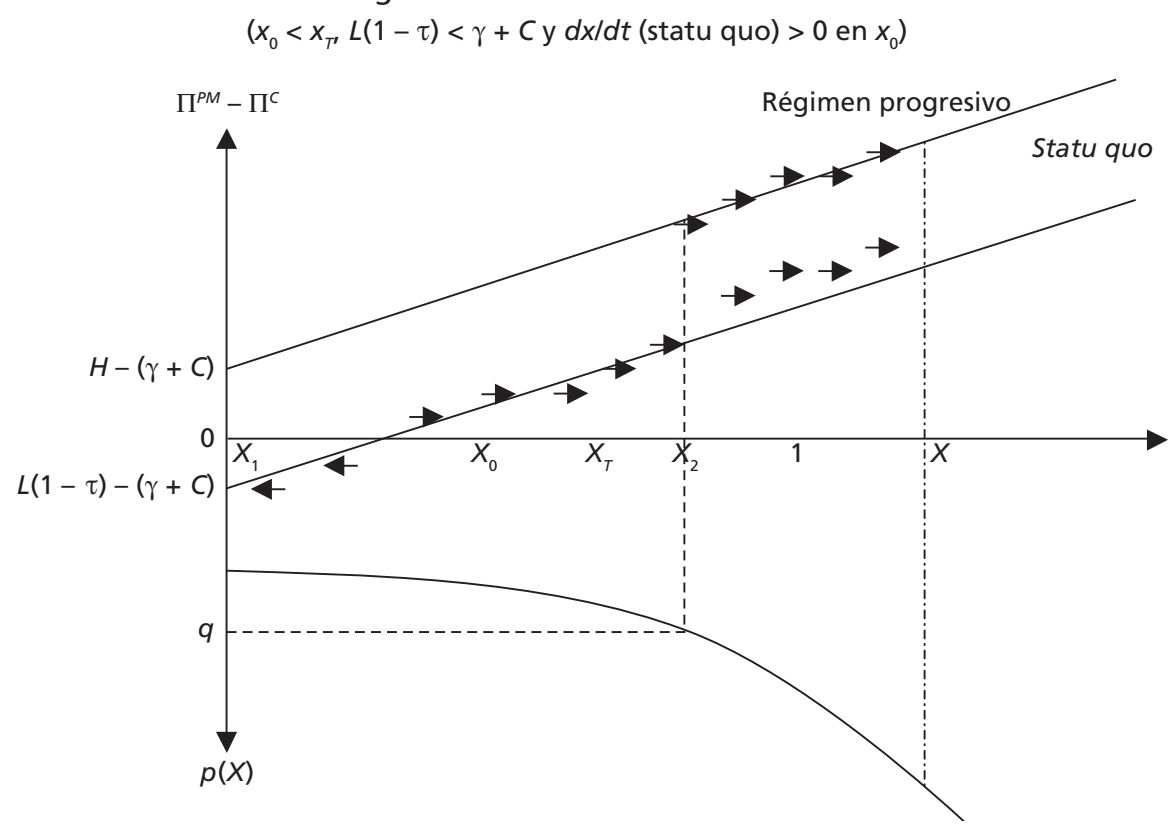


(es decir, diferentes trayectorias de desarrollo), en tanto que la presencia de países tipo $\mathrm{C}$ ayudará a identificar que el incremento en la variante participativa se asocia a una reforma institucional progresiva. Obviamente, si la base de datos no cuenta con una muestra suficientemente grande de países tipo $\mathrm{C}$, entonces, la influencia de los países A y B dominará en los resultados econométricos.

\section{Teoría de modernización y coevolución}

El modelo no está diseñado para analizar con lujo de detalle la coevolución entre factores económicos y culturales dado que variables económicas críticas se plantean como parámetros fijos. No obstante, el análisis gráfico de las expresiones (3) y (7) constituye una buena herramienta para explicar cómo una mejora exógena en las condiciones económicas propicia una transformación cultural $\mathrm{y}$, con ello, se inicia una ronda de mejoras institucionales. Por tanto, el modelo es compatible con una versión coevolutiva de la teoría de modernización, que también sugiere que la democracia puede ser establecida cuando un país ha alcanzado cierto nivel de desarrollo socioeconómico. Hasta ahora, las variables económicas, como la productividad en ambos regímenes institucionales $(H$ y $L)$ han sido consideradas fijas, pero el modelo puede especificar una cadena de causalidad que se inicia con el cambio en alguna de estas variables.

Supóngase que la condición inicial se ubica en el punto $x_{0}$ de la figura 5 , por lo que el bagaje histórico de la sociedad es compatible con instituciones extractivas. En este escenario el statu quo puede ser descrito como una trampa social ya que la pobre participación de la sociedad civil y su continua alienación de la toma-de-decisiones impide producir endógenamente la capacidad para solucionar problemas de acción colectiva. Sin embargo, si por alguna razón externa la productividad de la economía se incrementa $(\Delta L>0$, sin violar la condición (2) de tal forma que el intercepto del diferencial de beneficios en el statu quo se desplaza hacia arriba, entonces la sociedad puede iniciar un ciclo positivo de transformación cultural y desarrollo. En $x_{1}$ tiene lugar un incremento en la productividad que detiene la pulverización futura de la sociedad civil y, por ende, el ser conformista deja de "pagar". Posteriormente, los valores participativos comienzan a propagarse y un cambio drástico en las instituciones se produce al momento de cruzarse el umbral cultural. En otras palabras, el incremento exógeno en la productividad crea las condiciones culturales requeridas para hacer posible acciones colectivas y el establecimiento de la democracia. 
Figura 5. Teoría de modernización

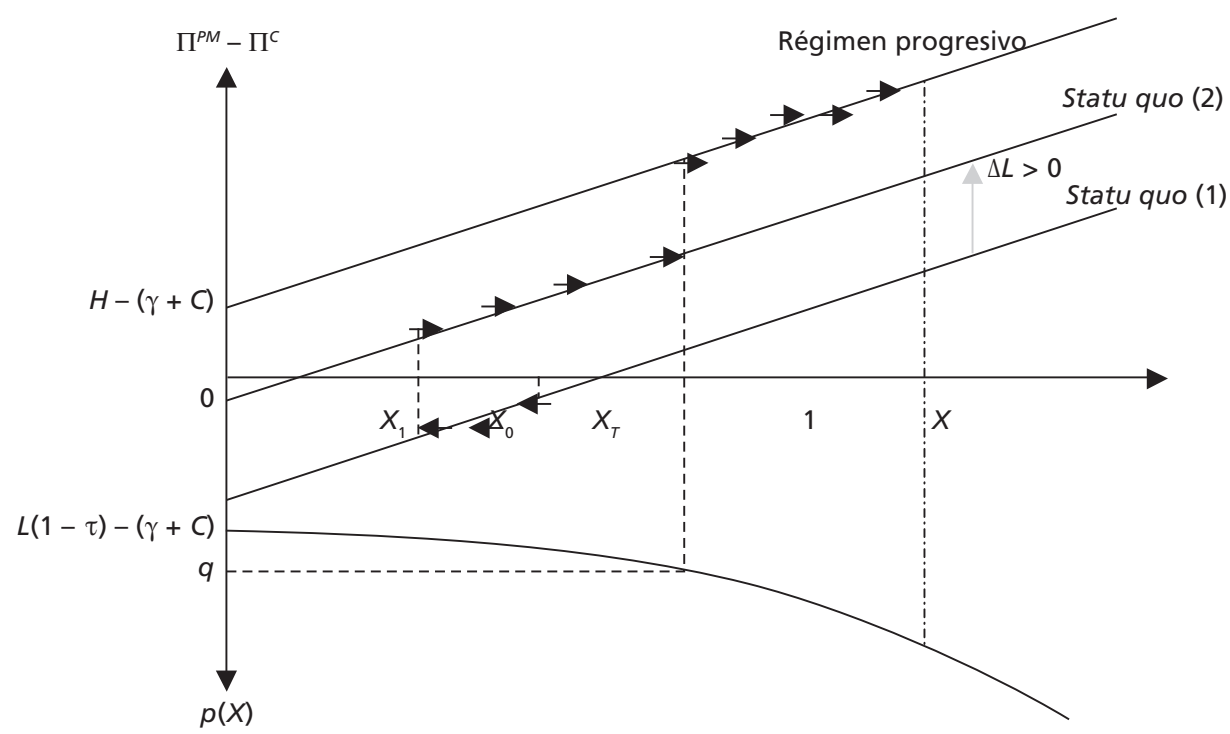

\section{DISPUTAS EN LA TRAYECTORIA HACIA LAS REFORMAS}

En los análisis previos, una sociedad puede moverse del statu quo al régimen progresivo sin que exista confrontación alguna entre los diferentes colectivos; es decir, los miembros participativos de la sociedad civil y las élites acuerdan las reformas a partir de negociaciones contenidas. Sin embargo, la evidencia histórica indica que las negociaciones caracterizadas por mecanismos políticos y canales formales de ingeniería institucional, como los debates parlamentarios y las votaciones, no son muy frecuentes cuando prevalece un régimen autoritario. En cambio, existen muchos episodios de la historia en los que la sociedad civil se moviliza y el gobierno responde con la fuerza militar y la violación flagrante de los derechos civiles y políticos. Revoluciones, manifestaciones populares, boicots y otras formas de disputas desbordadas tienen lugar antes de que los agraviados sean exitosos en sus planes de reforma y en lograr la democratización de la sociedad.

El modelo evolutivo que aquí se desarrolla también es capaz de describir este escenario empíricamente relevante una vez que las condiciones presentadas en (2) han sido descartadas. Estas son condiciones suficientes para que el statu quo y el régimen progresivo sean los únicos equilibrios bajo el criterio de heurísticas secuenciales, de tal manera que el legado histórico y el proceso de cambio 
cultural hacen posible la selección temporal o permanente de dichos equilibrios. Con otro conjunto de condiciones, la evolución de los valores participativos puede producir una trayectoria de desarrollo que va del statu quo al régimen desbordado y de éste al régimen progresivo. Las sociedades pueden experimentar un periodo de disputas desbordadas cuando se ubican dentro de un rango de valores culturales que alientan la combatividad por parte de los PM y la represión por parte de las élites.

\section{La construcción de una trayectoria de desarrollo}

En el modelo se puede establecer un conjunto de condiciones suficientes para construir una trayectoria de disputa-cum-reforma a lo largo de la cual los PM creen que sus derechos tienden a ser violados $(p<q)$. Esta trayectoria se puede caracterizar de la siguiente forma: etapa $i$ ) en la que las acciones elegidas son: "abusar" y "cumplir"; etapa $i$ ) en la que se elige "abusar" y "movilizarse"; etapa iii) en la que se opta por "respetar" y "movilizarse". Cabe notar que la etapa iii involucra una situación en la que las expectativas no se validan, ya que se parte de conjeturas con élites abusivas; no obstante, las élites prefieren respetar el nuevo régimen con instituciones no extractivas. En estas circunstancias, la experiencia respetuosa hace que las élites reduzcan el valor de $q$ con el paso del tiempo hasta hacer que las conjeturas sean consistentes. El modelo puede explicar endógenamente esta secuencia particular de desarrollo a partir de un incremento continuo en el número de miembros de la sociedad civil con valores participativos $(x)$. Por ende, es necesario especificar, en un primer paso, los rangos de $x$ en los que cada una de estas tres etapas se presenta.

Con la matriz de beneficios de la figura 1 es fácil encontrar el rango de valores de $x$ que hace viable a la etapa $i$. Al aplicar el concepto de solución secuencial y encontrar la acción elegida para cada actor se tiene que para todo $x \varepsilon$ $\left(x^{\prime}, x^{\prime \prime}\right)$ la sociedad se ubica en el statu quo, quedando el límite inferior y superior de este intervalo descrito por la siguiente expresión:

$$
\begin{aligned}
& x^{\prime}=\frac{B_{e}-R}{\tau L+B_{e}} \\
& x^{\prime \prime}=\frac{L(1-\tau)+H}{2 B_{s}} .
\end{aligned}
$$


Para la etapa $i i$ la solución secuencial requiere que, con una conjetura de élites abusivas, los PM prefieran movilizarse y las élites respondan abusivamente en concordancia con dicha expectativa. Así, para todo $x \in\left(x^{\prime \prime}, x^{\prime \prime \prime}\right)$ la sociedad transita por un periodo de disputas desbordadas quedando el límite superior del intervalo cerrado expresado de la siguiente manera: ${ }^{6}$

$$
x^{\prime \prime \prime}=\frac{B_{e}-R}{B_{e}} .
$$

En la etapa iii existe todavía una conjetura de élites abusivas y, por ello, los PM reaccionan movilizándose. Sin embargo, al aplicar el concepto de solución secuencial se desprende que las élites prefieren establecer nuevas instituciones a sabiendas de las acciones tomadas por los PM. Esta etapa de expectativas no cumplidas ocurre para valores de $x \varepsilon\left(x^{\prime \prime \prime}, 1\right)$ en donde el nivel del atributo cultural asociado con la probabilidad umbral $(p(x)=q)$ es tal que $x_{T}>1$.

En consecuencia, si la secuencia de desigualdades definidas en (11) se cumple, entonces, la trayectoria de disputa-cum-reforma se observa para un legado histórico en el que $x_{0} \varepsilon\left(x^{\prime}, x^{\prime \prime}\right)$, las conjeturas son tales que $p(x)<q$ para $x \varepsilon(0,1)$ y $x$ presenta una continua expansión ya que nunca "paga" ser un conformista. La propagación de los valores participativos se sostiene inclusive durante el periodo de disputas desbordadas, como se explica en el siguiente apartado.

$$
\frac{B_{e}-R}{\tau L+B_{e}}<\frac{L(1-\tau)+H}{2 B_{s}}<\frac{B_{e}-R}{B_{e}}<1<\frac{q[L(1-\tau)+H]-H}{B_{s}(2 q-1)} .
$$

\section{Dinámica cultural y movilizaciones}

El resultado del modelo ahora incluye un periodo de disputas desbordadas y, por ende, el diferencial de beneficios en la ecuación de duplicación debe ser modificado en un segundo paso, como se indica en la expresión (12). Por tanto, el beneficio para los PM en este régimen viene dado por $\Pi_{T R}^{P M}=B_{s} x-\gamma(1-x)$, de acuerdo con la esquina sureste de la matriz de beneficios. Asimismo, la línea que corresponde al diferencial de beneficios en el caso de disputas desbordadas siempre tiene un intercepto negativo y una pendiente que es mayor a la observada en

\footnotetext{
${ }^{6}$ Conviene aclarar que en este modelo los individuos pasan por un periodo de disputas desbordadas, no porque piensen que van a resultar victoriosos en el establecimiento de las agendas institucionales futuras, sino porque la misma movilización les genera beneficios directos.
} 
los otros dos regímenes. La función-en-pasos del diferencial de beneficios no se modifica como antes, en términos de conjeturas, sino a partir de las etapas previamente descritas.

$$
\frac{d x}{d t}=\mu x(1-x)\left[\Pi^{P M}-\Pi^{C}\right]
$$

en donde

$$
\Pi^{P M}-\Pi^{C}= \begin{cases}L(1-\tau)-(\gamma+C)+2 \gamma x & \text { cuando } x \text { se ubica en la etapa } i \\ -(\gamma+C)+\left(B_{s}+2 \gamma\right) x & \text { cuando } x \text { se ubica en la etapa } i i \\ H-(\gamma+C)+2 \gamma x & \text { cuando } x \text { se ubica en la etapa } i i i\end{cases}
$$

A pesar de que la condición (2) fue removida en este planteamiento, no es complicado probar que la expresión (3) sigue siendo una función de probabilidad para todos los valores de $x$ en el intervalo unitario, y que dicha curva presenta una inflexión en el punto $x$ ". La figura 6 ilustra la trayectoria de disputa-cum-

Figura 6. Disputas y reforma institucional

$$
\left(L(1-\tau)>\gamma+C, x^{\prime}<x_{0}<x^{\prime \prime}<x^{\prime \prime \prime}<1<x_{T}\right)
$$

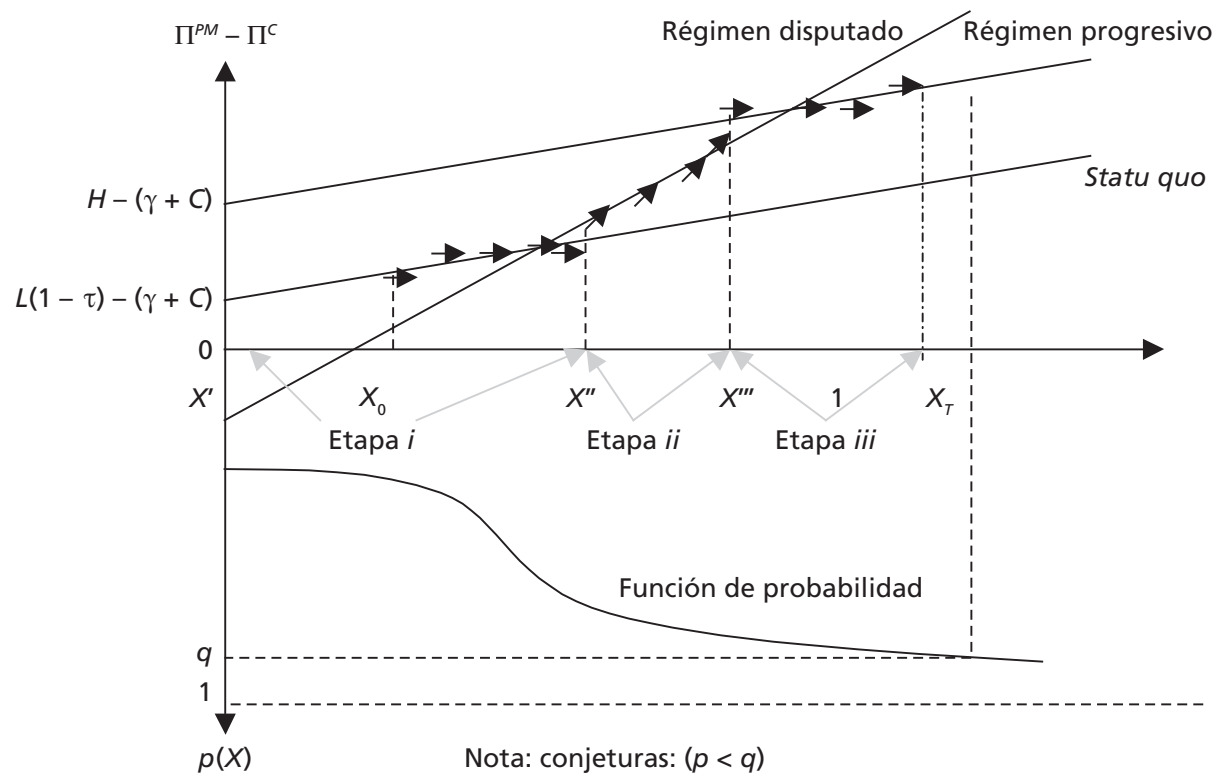


reforma al trazar el diferencial de beneficios de la ecuación de duplicación (12) en el cuadrante superior y la función de probabilidad en el cuadrante inferior para $p(x)<q$. Para poder observar un incremento continuo en $x$, a partir del legado histórico $x_{0}$, se supone que el diferencial de beneficios para el statu quo y para el régimen progresivo es positivo para todos los valores posibles del atributo cultural, mientras que el diferencial de beneficios para el régimen disputado es positivo en el rango relevante. También se supone que $x_{T}>1$, por lo que en el estado estacionario los valores participativos son compartidos por todos los miembros de la sociedad $(x=1)$. $^{7}$

\section{CONCLUSIONES}

El modelo evolutivo desarrollado en este artículo muestra que existen ciertas trayectorias y circunstancias que le permiten a un país democratizarse y crear instituciones no extractivas conducentes al crecimiento, en las que las élites están sujetas a la rendición de cuentas. Aunque la historia de cada país tiene matices muy particulares, analíticamente es factible hablar de clubes de desarrollo. Algunos países son capaces de dejar atrás un régimen autoritario mediante un proceso interno en el que las actitudes mentales y los comportamientos se modifican, otros se encuentran atrapados en una trampa de pobreza en la que se establecen candados que imposibilitan cualquier ruptura, mientras que otro más son capaces de escapar de dicha trampa si existen presiones internacionales sobre las élites o si se presenta algún factor exógeno de gran relevancia.

Por otra parte, la democratización y las reformas institucionales se hacen viables, en muchos casos, a partir de revueltas populares y episodios de represión violenta, pero en otros las instituciones progresivas son diseñadas a partir de negociaciones contenidas. El modelo de este artículo tiene la virtud de describir todas estas trayectorias de desarrollo mediante el mismo mecanismo social: la propagación de ciertos atributos culturales a partir de experiencias sociales y la solución de los problemas de acción colectiva a partir de una sociedad civil participativa.

\footnotetext{
${ }^{7}$ No es difícil mostrar que cuando $p(x) \geq q$ y $x_{T}<1$ la sociedad puede experimentar una regresión en su desarrollo institucional. Con una conjetura en la que se confía que los derechos van a ser respetados, los PM no son alentados a movilizarse dados los grandes beneficios que se pierden con las protestas. Esta reticencia hace que las élites prefieran las instituciones extractivas. En otras palabras, el modelo muestra que una mejora pronunciada en la calidad institucional puede ser contraproductiva si se crea una sociedad civil excesivamente confiada que no contribuye a desalentar el uso de instituciones extractivas mediante movilizaciones.
} 
Aunque el pensamiento neoclásico ha sido capaz de explicar la mecánica del crecimiento incorporando rendimientos crecientes a nivel agregado y otros elementos sugeridos por economistas de diferentes doctrinas de pensamiento (Aghion y Howitt, 1998), la pregunta clave para explicar el desarrollo socioeconómico no ha sido del todo analizada por este paradigma. No basta con argumentar que consideraciones estratégicas y el poder de las élites producen inercias institucionales, también es necesario investigar qué factores hacen factible que un amplio segmento de la sociedad civil se vuelva más contestatario y pueda involucrarse en el diseño institucional. Algunas sociedades han sido históricamente más exitosas que otras en resolver sus problemas de acción colectiva, de tal forma que sus ciudadanos han logrado coordinar sus acciones para romper con el statu quo.

Este artículo presenta argumentos formales que respaldan el uso de elementos culturales para responder a dicha interrogante y poder llenar el vacío teórico arriba referido. El que la evidencia empírica muestre una fuerte correlación entre valores culturales contemporáneos e indicadores de desempeño político/económico, y una correlación igualmente significativa entre el desempeño de las instituciones contemporáneas y factores históricos remotos, no es evidencia concluyente en favor de una teoría culturalista; sin embargo, estas fuertes asociaciones indudablemente sugieren que la investigación del desarrollo socioeconómico tiene que analizar la relevancia de la cultura y la historia. Aunque la teoría cultural elaborada en este artículo formaliza algunos argumentos de la "secuencia humana del desarrollo", y racionaliza parte de la evidencia empírica de Inglehart y Welzel (2005) y Tabellini (2008), resulta muy importante desarrollar estudios econométricos alternativos que puedan probar la coevolución entre variables endógenas e identificar cuáles son las variables relevantes que le dan forma al legado histórico de los países. 


\section{REFERENCIAS BIBLIOGRÁFICAS}

Acemoglu, Daron, Simon Johnson, y James Robinson (2001), "The Colonial Origins of Comparative Development: An Empirical Investigation", American Economic Review, núm. 91, pp. 1369-1401.

_ cracy", American Economic Review, en prensa.

— Simon Johnson, y James Robinson (2002), "Reversal of Fortune: Geography and Institutions in the Making of the Modern World Income Distribution", Quarterly Journal of Economics, núm.117, pp. 1231-1294.

— - y James Robinson (2006), Economic Origins of Dictatorship and Democracy, Nueva York, Cambridge University Press.

— - y James Robinson (2007a), "Persistence of Elites, Power and Institutions", American Economic Review, en prensa.

— y Simon Johnson (2005), "Unbundling Institutions”, Journal of Political Economy, núm. 113, pp. 949-995.

Aghion, Philippe, y Peter Howitt (1998), Endogenous Growth Theory, Cambridge, Ma., MIT Press.

Alesina, Alberto, y Eliana la Ferrara (2004), "Ethnic Diversity and Economic Performance”, NBER Working Paper, núm. 10313.

Barro, Robert J., y Rachel M. McCleary (2003), "Religion and Economic Growth", NBER Working paper, núm. 9682.

Berkowitz, Daniel, Katharina Pistor, y Jean-Francois Richard (2001), "Economic Development, Legality and the Transplant Effect", Working Paper, Department of Economics, University of Pittsburgh.

Blum, Bernardo S. (2003), "The Curse of Geography: a View About the Process of Wealth Creation and Distribution", Cuadernos de Economía, año 40, núm. 112, pp. 423-433.

Blum, Ulrich, y Leonard Dudley (2001), "Religion and Economic Growth: Was Weber Right?”, Journal of Evolutionary Economics 11, núm. 2, pp. 207-230.

Bourdieu, P. (1986), "The Forms of Capital”, en Richardson, J. G. (ed.), Handbook of Theory and Research for the Sociology of Education, Nueva York, Greenwood Press, pp. 241-258.

Bowles, Samuel (2004), Microeconomics: Behaviour, Institutions and Evolution, Princeton University Press.

Coleman, J. (1988), "Social Capital in the Creation of Human Capital", American Journal of Sociology, núm. 94, pp. 95-121. 
Engerman, Stanley L., y Kenneth L. Sokoloff (1997), "Factor Endowments, Institutions, and Differential Paths of Growth among New World Economies", en Haber, S. (ed.), How Latin America Fell Behind, California, Stanford University Press.

—, y Kenneth L. Sokoloff (2005), "Colonialism, Inequality and Long-run Paths of Development”, NBER, Working Paper, núm. 11057.

Easterly, William, y Ross Levine (1997), “Africa’s Growth Tragedy: Policies and Ethnic Divisions”, Quarterly Journal of Economics, 111(4), pp. 1203-1250.

— ce Economic Development”, NBER Working Paper, núm. 9106.

Frankel, Jeffrey, y David Romer, y Teresa L. Cyrus (1996), "Trade and Growth in East Asian Countries: Cause and Effect?”, NBER Working Paper, núm. 5732.

— - - (1999), "Does Trade Cause Growth?”, American Economic Review, 89(3), pp. 379-399.

Grier, Robin (1997), "The Effects of Religion on Economic Development: A Cross National Study of 63 Former Colonies", Kyklos 50, núm. 1, pp. 47-62.

Huntington, Samuel P. (1996), The Clash of Civilizations and the Remaking of the World Order, Nueva York, Simon and Schuster.

Inglehart, Ronald (1997), Modernization and Postmodernization: Cultural, Economic and Political Change in 43 Societies, Princeton: Princeton University Press.

— - y Christian Welzel (2005), Modernization, Cultural Change, and Democracy. The Human Development Sequence, Cambridge: Cambridge University Press.

Knight, Jack (1992), Institutions and Social Conflict, Nueva York, Cambridge University Press.

La Porta, Rafael, Florencio López-de-Silanes, y Andrei Shleifer (2008), "The Economic Consequences of Legal Origins", Journal of Economic Literature, 46:2, pp. 285-332.

Lipset, S.M. (1959), "Some Social Requisites of Democracy: Economic Development and Political Legitimacy", American Political Science Review, 53, pp. 69-105.

North, Douglas (1981), Structure and Change in Economic History, Nueva York, W.W. Norton \& Co.

Quah, Danny (1997), "Empirics for Growth and Distribution: Stratification, Polarization and Convergence Clubs", Journal of Economic Growth, 2, pp. 27-60.

Tabellini, Guido (2006), "Culture and Institutions: Economic Development in the Regions of Europe", IGIER, Bocconi University, mayo.

Putnam, R. (1993), Making Democracy Work: Civic Traditions in Modern Italy, Princeton: Princeton University Press. 
Sachs, Jeffery D. (2003), “Institutions don’t Rule: Direct Effects of Geography on per capita Income”, NBER, Working Paper, núm. 9490.

Sala-i-Martín, Xavier (1997), "I Just Ran Two Million Regressions”, American Economic Review, 87, núm. 2, pp. 178-183.

Tilly, Charles (2004), Contention \& Democracy in Europe, 1650-2000, Nueva York, Cambridge University Press.

Welzel, Christian, Ronald Inglehart, y Franziska Deutsch (2005), "Social Capital, Voluntary Associations and Collective Action: Which Aspects of Social Capital Have the Greatest Civic' Payoff?," Journal of Civil Society, 1, núm. 2, pp. 121-146.

— Ronald Inglehart y Hans-Dieter Klingemann (2003), "The Theory of Human Development: A Cross-Cultural Analysis", European Journal of Political Research, 42, pp. 341-379. 
